\title{
Fabrication of Soft Tissue Layers for 3D Printed Models in Dental Implant Education
}

Keywords: 3D printed model; Implant surgery education; Soft tissue layers; Cone Beam Computed Tomography

\begin{abstract}
The use of СВСТ has enabled the printing of the exact osseous anatomy of the patient, providing the dentist with the tactile simulation in implant placement to ensure a predictable and successful surgery. While these models have substantially enhanced the preparation and education of implant surgery, they lack the soft tissue layers necessary for simulating important procedures such as periosteal releasing incisions and primary closures. For a more realistic surgical simulation in implant education, the soft tissue layers of the oral mucosa as well as the Schneiderian membrane has been incorporated into the $3 \mathrm{D}$ printed model. In this article, the newly fabricated 3D model is introduced, and its representation of soft tissue layers is described.
\end{abstract}

\section{Introduction}

With the recent advances of $3 \mathrm{D}$ printing technology and computed tomography, the utilization of $3 \mathrm{D}$ models derived from Cone Beam Computed Tomography (СВCT) has become an increasingly accepted method of education in implant dentistry. The 3D printed model of a patient's skeletal structure offers a remarkable advantage in various stages of dental surgery, such as the assessment of the patient's anatomy, treatment planning, and simulation of surgery. The $3 \mathrm{D}$ printed model provides tactile information of the osseous surgical site that the 2D images of the CBCT cannot provide, and therefore increases the efficiency and success of dental implant surgery [1].

A complete surgical simulation, however, requires more than the hard tissue. The types of implant procedures that can benefit from simulation include incision design, flap elevation, osteotomy, implant placement, and Guided Bone Regeneration (GBR), each of which heavily involves the management of soft tissue. GBR, in particular, is an important therapeutic procedure for osseous defects, in which the regeneration of bone is mostly attained after a successful soft tissue closure. Therefore, soft tissue management is a necessary part of the 3D model simulation of implant surgery. The current method of achieving the hard and soft tissue data through CBCT for the 3D model, however, is insufficient. While dense oral structures such as bone and teeth are well defined in CBCT imaging, soft tissue contrast is inadequate for a thorough analysis [2]. As seen in Figure 1A, the soft tissue layers in the CBCT image are indistinct due to the overlap and similarity in contrast. CBCT also fails to differentiate the individual layers of soft tissue, such as the periosteum, lamina propria, and epithelium. Subsequently, the CBCT-derived 3D model lacks soft tissue information needed for the realistic simulation of procedures such as releasing incisions and tension free closures.

While 3D printed models are beginning to take a larger role in surgical simulation in implant dentistry, publications discussing the

\section{Journal of Oral Biology}

\section{Nahjin Park*, Asmita Bhekare, Yung Cheng Paul Yu, Jeffrey Scolnick and Peter M Loomer}

Department of Periodontology and Implant Dentistry, New York University, USA

\section{*Address for Correspondence}

Nahjin Park, Department of Periodontology and Implant Dentistry, New York University, Clinic 5W, 345 E 24th St, New York, NY 10010, USA, Tel: +1-347-279-2958; E-mail: Np1002@nyu.edu

Submission: 17 May, 2017

Accepted: 30 June, 2017

Published: 06 July, 2017

Copyright: () 2017 Park N, et al. This is an open access article distributed under the Creative Commons Attribution License, which permits unrestricted use, distribution, and reproduction in any medium, provided the original work is properly cited.

fabrication of the soft tissue for education purposes remain scarce. An ideal model for surgical simulation should include the soft tissue, vasculature, and nerve structure that would help the dentist prepare for implant surgery and the complications that can follow. The current technology in $3 \mathrm{D}$ printing and imaging, however, presents with limitations in representing soft tissue layers onto the hard tissue model. The purpose of this report is to document and discuss the simulation of the soft and hard tissue necessary for the surgical simulation with 3D printed models in implant dentistry.

\section{Materials and Methods}

In order to simulate the hard and soft tissues with the $3 \mathrm{D}$ printed model (Figures 1A-C), first the patient's CBCT image was taken with a CBCT imaging system (J. Morita, Kyoto, Japan). The field of view (FOV) of the image was selected depending on the area of interest of the patient. In the cases presented in this article, a FOV of 5 to 7 $\mathrm{cm}$ was selected to assess the entire maxillary arch for the implant sites. Then, the DICOM (Digital Imaging and Communications in Medicine) files from the CВCT image were all converted into the Stereolithography (STL) format through a 3D rendering software.

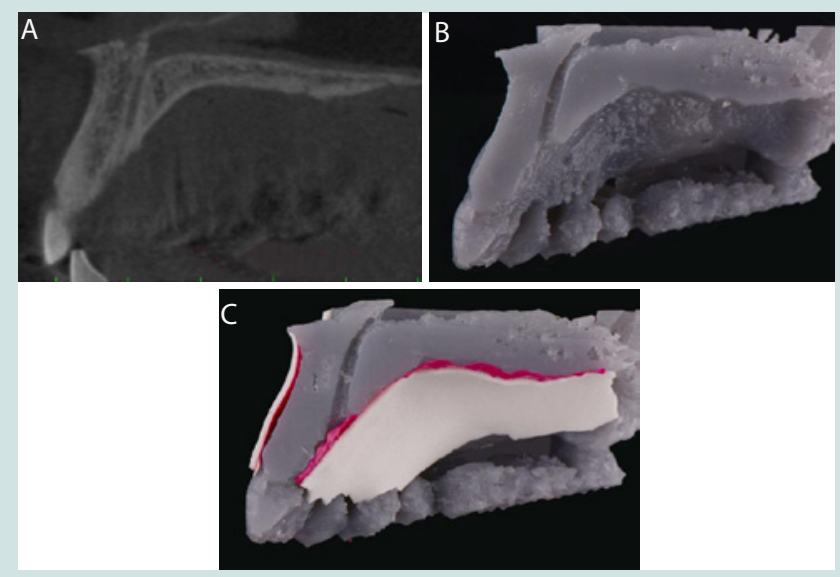

Figure 1: A: Case 1.CBCT image of maxillary cross section. B: Case 1. Current available 3D printed model. C: Case 1. Enhanced 3D printed model. 
Citation: Park N, Bhekare A, Yu YCP, Scolnick J, Loomer PM. Fabrication of Soft Tissue Layers for 3D Printed Models in Dental Implant Education. J Oral Biol. 2017; 4(1): 3

Then, we selected the area of interest for surgery or anatomical evaluation and surgical simulation. For example, for the patient shown in Figure 1A, the maxillary region spanning from the dissected incisive canal to the posterior right molar was selected in order to acquire the maxillary sinus structure for the surgical simulation of sinus augmentation. The files were then processed and then printed by the Formlab Form 2 Printer (Formlabs, Somerville, MA), using a grey methacrylic photoreactive liquid resin material (Figures 2A-C). Once the hard tissue of the model was printed and complete, the soft tissue layers necessary for a surgical flap and wound closure simulation were fabricated for the new prototype (Figures 3A-D). Vinyl tape was used to reproduce the periosteum, and a soft sponge tape was used to replicate the lamina propria, both of which were fabricated by a cutting device that allowed reproducibility. These layers were then adhered to the $3 \mathrm{D}$ printed model. The Schneiderian membrane of the maxillary sinus and the outer mucosa was recreated with liquid tape, which was layered onto the inner surface of the printed model and on top of the soft sponge (Tables 1 and 2).

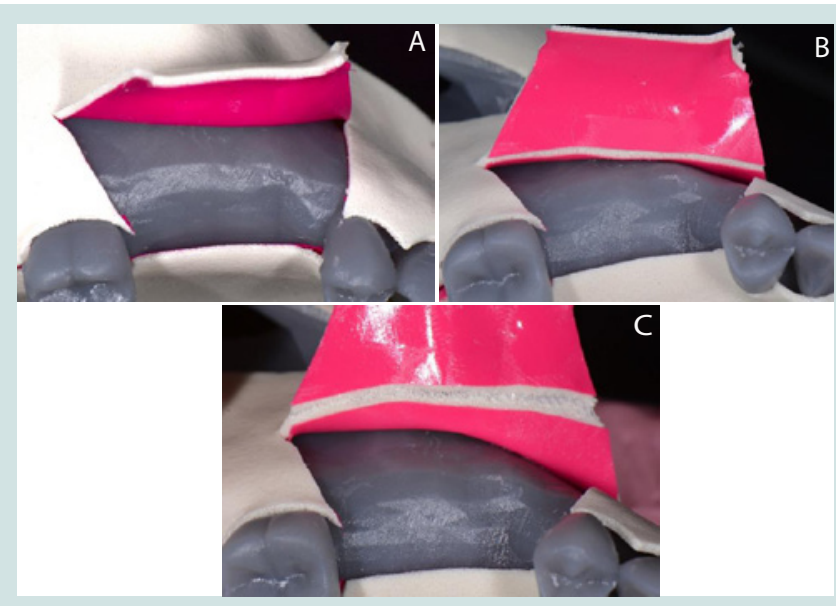

Figure 2: A: Case 2. Simulation of a periosteal flap elevation on the 3D mode B: Case 2. Simulation of a periosteal releasing incision on the 3D model. C: Case 2 . The increased mobility of the flap after the releasing incision.
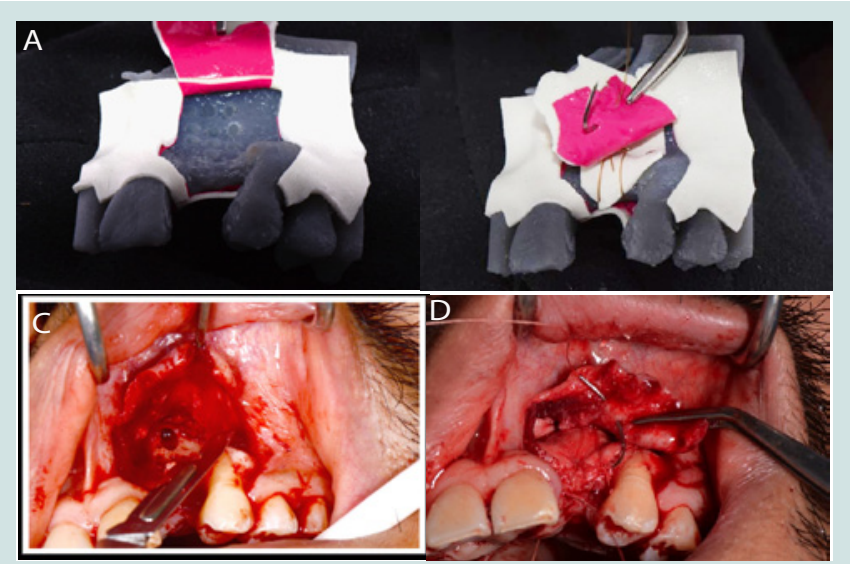

Figure 3: A: Case 3. Simulation of a periosteal releasing incision on the 3D model. B: Case 3.Simulation of a periosteal mattress suture on the 3D model. C: Case 3. Periosteal releasing incision as planned on the patient's 3D printed model. D: Case 3.Periosteal mattress suture as planned on the patient's 3D printed model.
Table 1: Summary table of simulated tissues and materials used for the fabrication of the models.

\begin{tabular}{|c|c|c|c|}
\hline Tissue Type & Tissue Layer & Material & Method \\
\hline \multirow{2}{*}{ Bone } & Cancellous bone & \multirow{2}{*}{$\begin{array}{l}\text { Photopolymerized } \\
\text { Resin }\end{array}$} & \multirow{2}{*}{$\begin{array}{l}\text { Stereolithography } \\
\text { (STL) 3D printed }\end{array}$} \\
\hline & Cortical bone & & \\
\hline \multirow[b]{3}{*}{ Soft Tissue } & Periosteum & Vinyl Tape & \multirow{2}{*}{$\begin{array}{c}2 \mathrm{D} \text { cutting } \\
\text { machine used }\end{array}$} \\
\hline & Lamina propria & Soft sponge & \\
\hline & $\begin{array}{l}\text { Epithelium and } \\
\text { Schneiderian } \\
\text { membrane }\end{array}$ & Liquid Tape & Painted manually \\
\hline
\end{tabular}

Table 2: Soft tissue layers of the oral mucosa
Epithelium

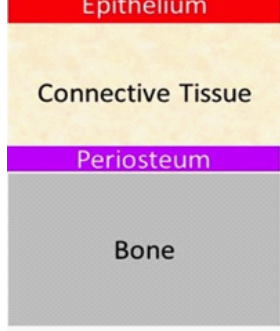

Real Tissue

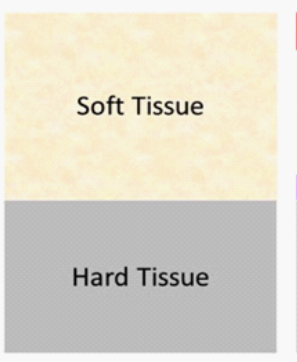

CBCT Image
Liquid Tape

Sponge Tape

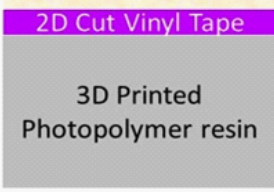

2D/3D Printed Model

\section{Results}

The two augmentation surgeries presented in this report were carried out after the dentist had simulated and practiced the surgery onto the enhanced 3D model. Case 1 in Figures $1 \mathrm{~A}-\mathrm{C}$ shows the enhanced 3D model, and Case 2 in Figures 2A-C shows the periosteal releasing incision simulated onto the $3 \mathrm{D}$ model. Finally, Case 3 presented in Figures 3A-D shows both the periosteal releasing incision and periosteal mattress suture simulated then carried out during an implant surgery. Each surgical site was examined with follow up visits of 6 months and 12 months respectively, and showed uncomplicated healing.

\section{Discussion}

\section{CBCT versus MRI}

CBCT is an imaging technique that utilizes ionizing radiation (X-rays) to penetrate and capture the structure of solid body tissues in three dimensions. The more dense the tissue, the more radiation is absorbed, so that the resulting image shows clear borders of structures necessary for implant treatment planning such as the cortical bone, cancellous bone, periodontal ligament, lamina dura, enamel, dentin, and pulp. The major advantage of CBCT over the conventional CT scan is the reduced radiation dose for $3 \mathrm{D}$ visualization of the patient. The CBCT resolution of soft tissue layers, however, is low, and is often interrupted by beam hardening artifacts and scatter radiation [2].

Another 3D imaging technique is Magnetic Resonance Imaging (MRI). MRI uses a strong magnetic field that aligns the hydrogen atoms within the patient, and then detects the energy released by these atoms to localize the tissues of the body. Because hydrogen is found mostly in soft tissue, MRI captures the soft tissue layers in excellent detail. However, its resolution for hard tissue is poor [3]. While soft tissue information is essential in fabricating an effective $3 \mathrm{D}$ model, the simulation model cannot be printed without accurate hard 
tissue information. Also, the high cost associated with MRI usually reserves this diagnostic exam for specific indications [4]. For these reasons, despite its shortcomings in soft tissue resolution, CBCT is favored over MRI for the fabrication of the 3D printed model.

\section{Importance of soft tissue management in implant surgery}

While the hard tissue captured by СBCT is essential for a $3 \mathrm{D}$ printed model, a soft tissue representation is also necessary for an accurate surgical simulation. In GBR, for example, the management of soft tissue is a crucial step for optimal healing. A successful closure of the wound enables re-epithelialization, wound contraction, collagen and overall tissue remodeling that stabilizes the implant site. Primary intention and secondary intention healing are the two types of wound closure, the former indicating a full coverage of the wound with soft tissue and the latter a compromised closure that requires collagen remodeling and often results in scar formation [5]. Therefore, the training of soft tissue management is crucial in implant surgical education in order to yield predictable outcomes, and the $3 \mathrm{D}$ printed model presents a significant advantage in this area when equipped with additional coatings that simulate the soft tissue layers.

\section{The role of periosteum in surgery}

The periosteum is a dense layer of vascular connective tissue enveloping the bones. In GBR a periosteal releasing incision increases the flap elasticity and enables the advancement of the soft tissue over the surgical site to achieve a tension free closure [6]. In surgeries, a proper manipulation of the periosteum while achieving primary closure is essential for the healing of the soft tissues due to the enhanced blood supply provided by the connective tissue above the periosteum. The periosteum, therefore, is a crucial soft tissue layer that influences the success of implant surgery [7].

As a result, the new 3D model was fabricated with the addition of soft tissue elements that present the opportunity to simulate the incision design, flap elevation, osteotomy, implant placement, and closure. Figures $2 \mathrm{~A}$ and $3 \mathrm{~B}$ show the simulation of a periosteal releasing incision and periosteal mattress suture with the $3 \mathrm{D}$ model. Figures 3A-D show the actual clinical procedure of a periosteal releasing incision and periosteal mattress suture simulated on the patient's 3D printed model. While further improvements are to be made, the revised model presents a significant advantage in implant education within the current boundaries of 3D printing technology and CBCT.

\section{Conclusion}

$3 \mathrm{D}$ printed models from CBCT images have presented various advantages in surgical preparation and simulation in the past. While $\mathrm{CBCT}$ has been the favorable method over MRI in achieving the 3D visualization of hard tissues for the printed models, the challenge of adding soft tissue layers to the model has yet to be addressed. Because soft tissue management is essential in various procedures in implant dentistry, we simulated and added the periosteum, connective tissue, and epithelium layers onto the $3 \mathrm{D}$ printed model. This model provides hands on educational experience as the dentist is allowed to fabricate multiple replicas of soft tissues on the patient-specific model, and repeat the procedure until he or she reaches a level of confidence. In the near future, the integration of MRI with CBCT may allow the production of even more realistic soft tissue architecture for surgical simulation.

\section{References}

1. Froum SJ, Cho SC, Loomer PM, Georgantza A, Suzuki T, et al. (2016) The use of 3D printing in dental implant education. Dent Learning 1-13.

2. Shah N, Bansal N, Logani A (2014) Recent advances in imaging technologies in dentistry. World J Radiol 10: 794-807.

3. Law CP, Chandra RV, Hoang JK, Phal PM (2011) Imaging the oral cavity: key concepts for the radiologist. Br J Radiol 84: 944-957.

4. Chang AE, Matory YL, Dwyer AJ, Hill SC, Girton ME, et al. (1987) Magnetic resonance imaging versus computed tomography in the evaluation of soft tissue tumors of the extremities. Ann Surg 205: 340-348.

5. Wang H, Boyapati L (2006) "PASS" principles for predictable bone regeneration. Implant Dent 15: 8-17.

6. Romanos GE (2010) Periosteal releasing incision for successful coverage of augmented sites. A technical note. J Oral Implantol 36: 25-30.

7. Cho EH, Park JC, Cha JK, Kim YT, Jung UW, et al. (2011) Dimensional change of the healed periosteum on surgically created defects. J Periodontal Implant Sci 41: 176-184. 